American Journal of Applied Sciences 7 (4): 551-555, 2010

ISSN 1546-9239

(C) 2010Science Publications

\title{
Fade Margin Analysis Due to Duststorm Based on Visibility Data Measured in a Desert
}

\author{
Md. Rafiqul Islam, Zain Elabdin Elshaikh, Othman O. Khalifa, \\ A.H.M. Zahirul Alam and Sheroz Khan \\ Wireless Communication and Signal Processing Research Group, \\ Faculty of Engineering, International Islamic University Malaysia, \\ Jalan Gombak, 53100 Kuala Lumpur, Malaysia
}

\begin{abstract}
Problem statement: The fade margin analysis of microwave propagation in areas affected by duststorm had been presented in this study. Approach: Based on long term duststorm data recorded in Riyadh-Saudi Arabia, the fade margin due to duststorm effects estimated. Results: The fade margin due to duststorm then derived under various water contents during the storm. Conclusion/Recommendations: It was particularly shown that duststorm have comparable effects on link reliability for typical storms.
\end{abstract}

Key words: Dust attenuation, dust fade margin, microwave links, visibility

\section{INTRODUCTION}

Duststorms occur in many parts of the world, especially in the Middle East and arid parts of Asia, as well as in the southwest of the USA, in the dry states, such as Texas and Arizona. Signal attenuation is an important parameter in telecommunications applications because of its importance in determining signal strength as a function of distance. A major cause of this phenomenon is atmospheric particles which can seriously limit the performance of telecommunication system especially at microwave level (Crane, 1971; Wesely et al., 2002).

Wind speed, atmospheric stability and source region surface characteristics are the three main environmental factors that affect the probability of occurrence, intensity and height of duststorms. Indicators of environmental change have been developed to reflect the anthropogenic pressure, current condition and the human response to such threatening processes as accelerated erosion and disturbance of nutrient cycling through loss of surface soil.

Riyadh, situated in the middle of the Saudi desert, is used to experience regular sandstorms. On March 10, 2009 a giant dust storm swept in from the desert and enveloped large parts of the Saudi capital Riyadh as shown in Fig. 1 (China Daily, 2009). In a matter of 30 $\mathrm{sec}$, visibility dropped from miles to just a few meters.

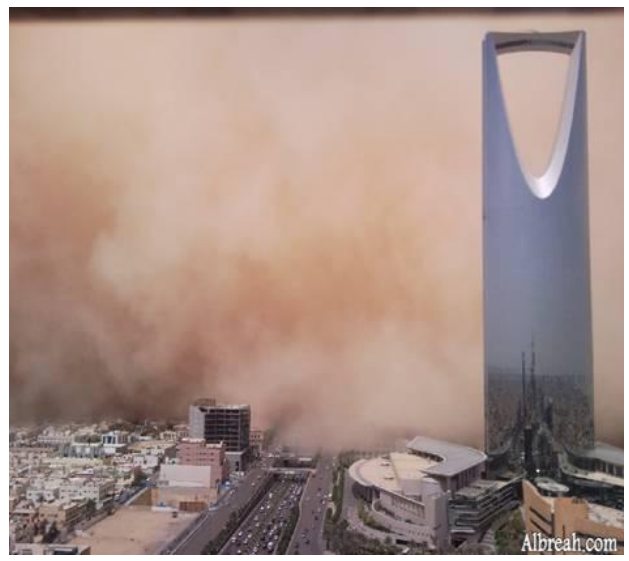

Fig. 1: A photograph giving a frontal view of the duststorm approaching Riyadh in March 10, 2009

\section{MATERIALS AND METHODS}

Duststorm prediction model: A mathematical model has been developed based on scattering effect of electromagnetic wave on dust particles (Elshaikh et al., 2009). It has been derived using Mie solution of Maxwell's equations. The proposed model can predict the duststorm attenuation for microwave frequency range with dust dielectric permittivity and visibility data.

Corresponding Author: Md. Rafiqul Islam, Wireless Communication and Signal Processing Research Group, Faculty of Engineering, International Islamic University Malaysia, Jalan Gombak, 53100 Kuala Lumpur, Malaysia 
Am. J. Applied Sci., 7 (4): 551-555, 2010

The specific attenuation $\mathrm{A}_{\mathrm{d}}\left(\mathrm{dB} \quad \mathrm{km}^{-1}\right)$ characterizing the duststorm can be written as (Elshaikh et al., 2009):

$$
A_{d}=\frac{a_{e} f}{V}\left(X+Y_{e_{e}}{ }^{2} f^{2}+Z_{e}{ }^{3} f^{3}\right)\left[d B ~ k m^{-1}\right]
$$

Where:

$$
\begin{aligned}
\mathrm{a}_{\mathrm{e}} & =\text { The equivalent particle radius in meters } \\
\mathrm{V} & \text { The visibility in } \mathrm{km} \\
\mathrm{f} & \text { The frequency in } \mathrm{GHz} \\
\mathrm{x}, \mathrm{y} \text { and } \mathrm{z}= & \text { Constants whose values depend on real } \\
& \left(\varepsilon^{\prime}\right) \text { and imaginary part }\left(\varepsilon^{\prime \prime}\right) \text { of the } \\
& \text { dielectric constant of the particles as: }
\end{aligned}
$$

$X=\frac{1886 \cdot \varepsilon^{\prime \prime}}{\left(\varepsilon^{\prime}+2\right)^{2}+\varepsilon^{\prime \prime 2}}$

$$
Y=137 \times 10^{3} \cdot \varepsilon^{\prime \prime}\left\{\begin{array}{l}
\frac{6}{5} \frac{7 \varepsilon^{\prime 2}+7 \varepsilon^{\prime \prime 2}+4 \varepsilon^{\prime}-20}{\left[\left(\varepsilon^{\prime}+2\right)^{2}+\varepsilon^{\prime \prime 2}\right]^{2}}+\frac{1}{15} \\
+\frac{5}{3\left[\left(2 \varepsilon^{\prime}+3\right)^{2}+4 \varepsilon^{\prime \prime 2}\right]}
\end{array}\right\}
$$

$$
\begin{aligned}
& Z=379 \times 10^{4} \\
& \left\{\frac{\left(\varepsilon^{\prime}-1\right)^{2}\left(\varepsilon^{\prime}+2\right)+\left[2\left(\varepsilon^{\prime}-1\right)\left(\varepsilon^{\prime}+2\right)-9\right]+\varepsilon^{\prime \prime}}{\left[\left(\varepsilon^{\prime}+2\right)^{2}+\varepsilon^{\prime \prime 2}\right]^{2}}\right\}
\end{aligned}
$$

The Eq. 1 has been used to estimate Fade Margins based on long term visibility data measured in RiyadhSaudi Arabia Fade margins are predicted for four frequency bands.

Visibility measurement of duststorm: Long term duststorm data were recorded in Riyadh-Saudi Arabia. Riyadh, situated in the middle of the Saudi desert and is used to face frequent duststorms.

The aim of collecting visibility data is to use the available data to estimate the effect of duststorm on fade margin and link reliability. Table 1 shows an average time per year for which visibility was deduced based on 15 years recorded at Riyadh in Saudi Arabia (Alhaider, 1986).

By re-arranging the Table 1, for the city of Riyadh, average number of minutes per year which visibilities were recorded below a certain values are shown in Table 2. The last column gives percentage of availability during the year. Based on the duststorm visibility data recorded in Riiyadh, the outage due to duststorm effects has been investigated in dust fade analysis for Riyadh.
Table 1: Average time per year for which visibility was recorded based on 15 years record at Riyadh, Saudi Arabia

\begin{tabular}{ll}
\hline Visibility $(\mathrm{m})$ & Average No. of min/year at Riyadh \\
\hline$\leq 10$ & 24 \\
$\leq 100$ & 690 \\
$\leq 200$ & 870 \\
$\leq 300$ & 1272 \\
$\leq 400$ & 1502 \\
$\leq 500$ & 2222 \\
\hline
\end{tabular}

Table 2: Percentage of time year ${ }^{-1}$ which visibility was recorded below the shown value at Riyadh

\begin{tabular}{lcl}
\hline Visibility $(\mathrm{m})$ & Avg. no. of min year & \\
\hline$\leq 10$ & 24 & Percentage of time year \\
\hline$\leq 100$ & 690 & 0.005 \\
$\leq 200$ & 870 & 0.130 \\
$\leq 300$ & 1227 & 0.170 \\
$\leq 400$ & 1502 & 0.230 \\
$\leq 500$ & 2222 & 0.290 \\
\end{tabular}

Table 3: Duststorm prediction attenuation $\mathrm{dB} \mathrm{km}^{-1}$ for Riyadh 10, 14, 23 and $40 \mathrm{GHZ}$

\begin{tabular}{lcllll}
\hline Freq. (GHz) & $\mathrm{V}(\mathrm{m})$ & Time $(\%)$ & $0 \%$ water & $2 \%$ water & $4 \%$ water \\
\hline 10 & 10 & 0.010 & 0.59 & 1.76 & 2.16 \\
& 100 & 0.130 & 0.06 & 0.18 & 0.22 \\
& 200 & 0.170 & 0.03 & 0.09 & 0.11 \\
& 300 & 0.230 & 0.02 & 0.06 & 0.07 \\
400 & 0.290 & 0.02 & 0.04 & 0.05 \\
& 500 & 0.420 & 0.01 & 0.04 & 0.04 \\
14 & 10 & 0.010 & 0.82 & 2.47 & 3.02 \\
& 100 & 0.130 & 0.08 & 0.25 & 0.30 \\
& 200 & 0.170 & 0.04 & 0.12 & 0.15 \\
& 300 & 0.230 & 0.03 & 0.08 & 0.10 \\
& 400 & 0.290 & 0.02 & 0.06 & 0.08 \\
& 500 & 0.420 & 0.02 & 0.05 & 0.06 \\
& 10 & 0.005 & 1.35 & 4.05 & 4.99 \\
& 100 & 0.130 & 0.14 & 0.41 & 0.50 \\
& 200 & 0.170 & 0.07 & 0.20 & 0.25 \\
& 300 & 0.230 & 0.05 & 0.14 & 0.17 \\
40 & 400 & 0.290 & 0.03 & 0.10 & 0.12 \\
& 500 & 0.420 & 0.03 & 0.08 & 0.10 \\
& 10 & 0.010 & 2.35 & 7.05 & 8.64 \\
& 100 & 0.130 & 0.24 & 0.70 & 0.86 \\
& 200 & 0.170 & 0.12 & 0.35 & 0.43 \\
& 300 & 0.230 & 0.08 & 0.24 & 0.29 \\
& 400 & 0.290 & 0.06 & 0.18 & 0.22 \\
& 500 & 0.420 & 0.05 & 0.14 & 0.17 \\
\hline
\end{tabular}

Dust fade analysis for Riyadh: Fifteen years recorded duststorms data in Riyadh are used to estimate the fade due to duststorms at $\mathrm{X}$-Band $(10 \mathrm{GHz}), \mathrm{ku}-\mathrm{Band}$ (14 GHz), ka-Band $(23 \mathrm{GHz})$ and V-Band $(40 \mathrm{GHz})$.

Average number of minutes per year which visibility was recorded below a certain value are shown in Table 2. The last column gives percentage of of time per year which visibility was recorded below the certain values.

Table 3 presents predicted duststorm attenuation values estimated using the proposed model for Quartz at a frequency for X-Band (10 GHz), ku-Band (14 $\mathrm{GHz})$, ka-Band (23 GHz) and V-Band (40 GHz). Three 
moisture contents are considered in the analysis. Attenuation are predicted for measured visibilities of $10,100,200,300,400$ and $500 \mathrm{~m}$ at equivalent dust particle radius $\left(\mathrm{a}_{\mathrm{e}}\right)$ of $30 \mu \mathrm{m}$.

Attenuation caused by duststorm at different visibilities ranges and different frequencies are estimated and plotted in Fig. 2-5. Predicted attenuations are estimated at 10,14, 23 and $40 \mathrm{GHz}$ for the various humidity conditions at 0,2 and $4 \%$ of water content (Ghobrial, 1980; Sharief, 1995). Figure 2-5 are based on the measured six visibility conditions as given in Table 1.

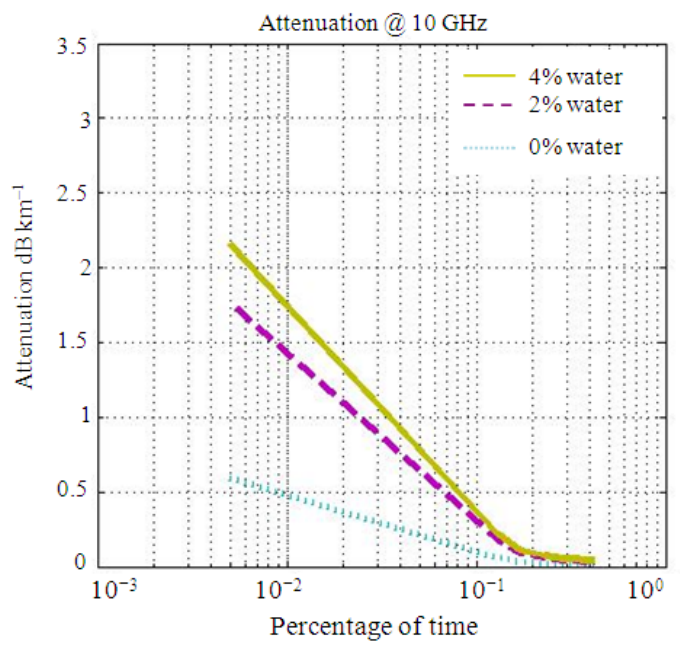

Fig. 2: Predicted dust fade at $10 \mathrm{GHz}$ based on measured visibilities in Riyadh

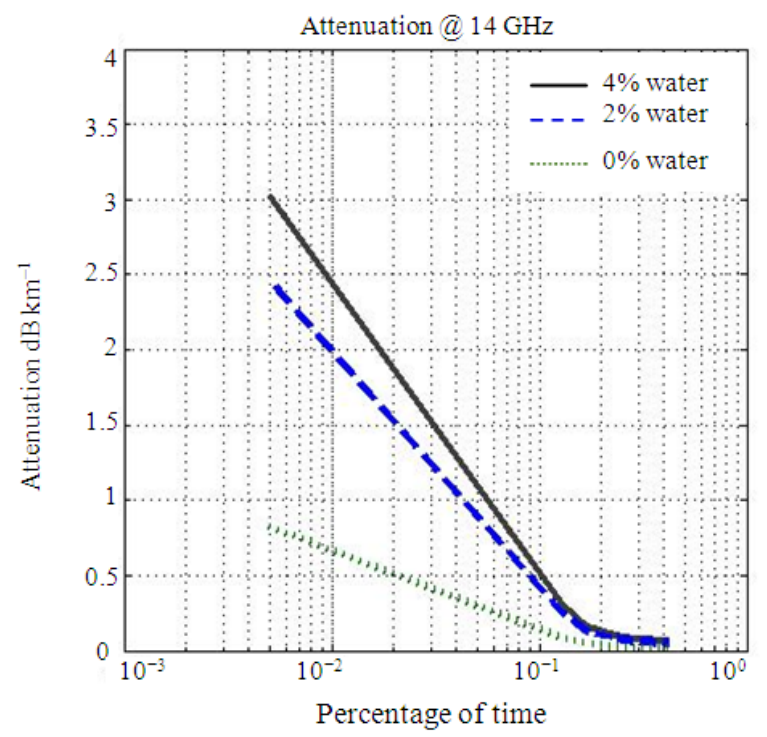

Fig. 3: Predicted dust fade at $14 \mathrm{GHz}$ based on measured visibilities in Riyadh
From Fig. 2-5, show that the dust fade at Riyadh increases markedly with increasing of frequency. The dust fade also increases with decreasing of visibilities. It changes rapidly with moisture content during the duststorm.

As moisture rises, the dust fade increases significantly. For $10 \mathrm{GHz}$ link, for moisture content of $0 \%$ the fade is $0.6 \mathrm{~dB} \mathrm{~km}^{-1}$ while for $4 \%$ it is about $2.2 \mathrm{~dB} \mathrm{~km}^{-1}$. Visibility was recorded below $10 \mathrm{~m}$ which indicates $0.005 \%$ of time per year at Riyadh.

At $40 \mathrm{GHz}$, the fade is higher than $9 \mathrm{~dB} \mathrm{~km}^{-1}$ with visibility of $10 \mathrm{~m}$ and moisture content of $4 \%$ while for $23 \mathrm{GHz}$, the fade is less than $5 \mathrm{~dB} \mathrm{~km}^{-1}$ for same moisture content.

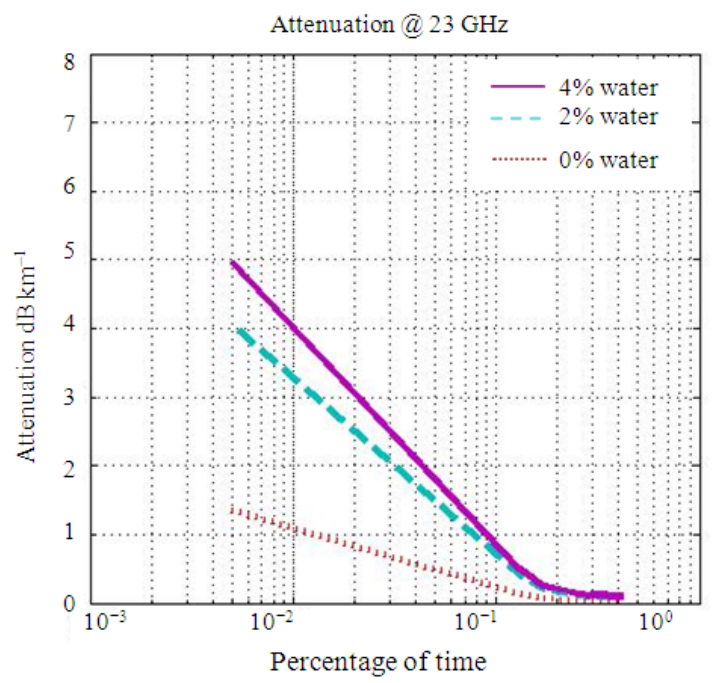

Fig. 4: Predicted dust fade at $23 \mathrm{GHz}$ based on measured visibilities in Riyadh

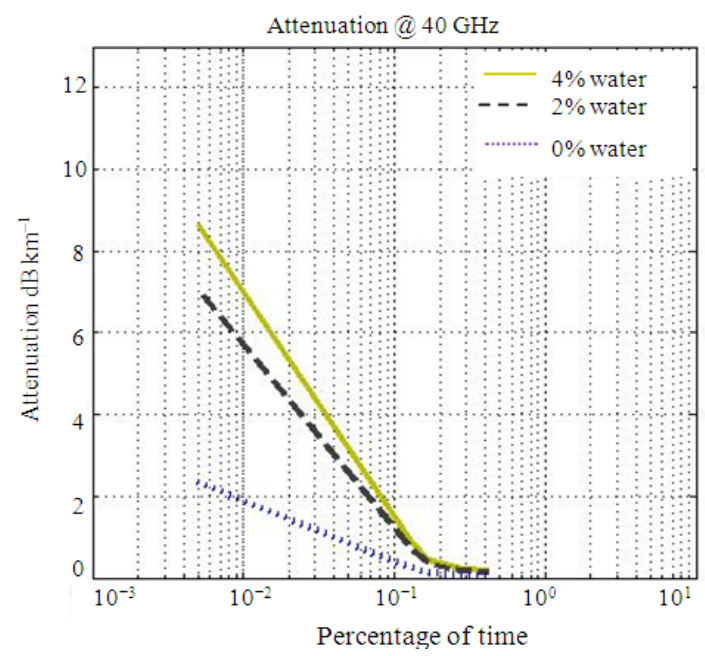

Fig. 5: Predicted dust fade at $40 \mathrm{GHz}$. based on measured visibilities in Riyadh 


\section{RESULTS AND DISCUSSION}

Fade margin analysis: The available data on duststorm, measured at Riyadh-Saudi Arabia, are used in Fade margin analysis to estimate the link's reliability. For worst case of $4 \%$ of water content, the fade margins are predicted with corresponding availabilities at Riyadh for four different frequencies 10, 14, 23 and $40 \mathrm{GHz}$ and plotted in Fig. 6.

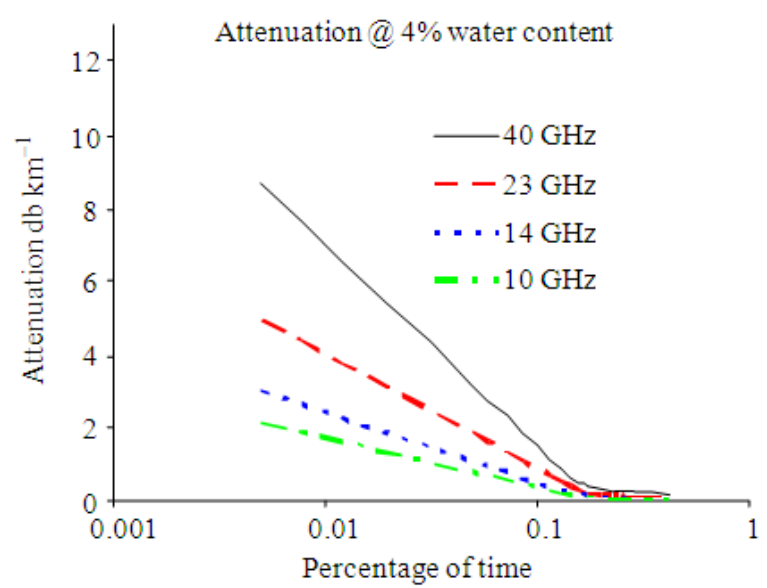

Fig. 6: Duststorm fade margins at 10, 14, 23 and $40 \mathrm{GHz}$ for Riyadh at $4 \%$ water content

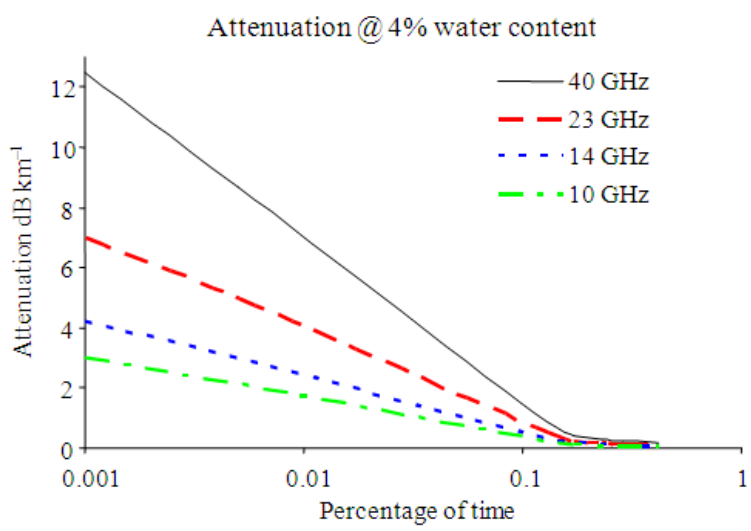

Fig. 7: Predicted Worst case duststorm fade margins variations with outage percentages for Riyadh with $4 \%$ water content at $10,14,23$ and $40 \mathrm{GHz}$

Table 4: Total attenuation value per $\mathrm{dB}$ for microwave links of $20 \mathrm{~km}$ at different reliability objectives at Riyadh

\begin{tabular}{lccc}
\hline $\begin{array}{l}\text { Frequency } \\
\text { bands }\end{array}$ & $\begin{array}{l}\text { Reliability } \\
99.9 \%\end{array}$ & $\begin{array}{l}\text { Reliability } \\
99.99 \%\end{array}$ & $\begin{array}{l}\text { Reliability } \\
99.999 \%\end{array}$ \\
\hline C-band & 8 & 36 & 64 \\
Ku-band & 10 & 50 & 90 \\
Ka-band & 18 & 80 & 140 \\
V-band & 36 & 140 & 240 \\
\hline
\end{tabular}

The duststorm visibility data collected from Riyadh is up to $10 \mathrm{~m}$. Hence, the outage percentage reaches to $0.005 \%$. In order to obtain the outage percentage of time from $0.001-1 \%$ during which attenuation was exceeded Fig. 6 is extrapolated and presented in Fig. 7 for Riyadh.

By assuming that the duststorm intensities are uniformly distributed along the path for tenth of kilometers which are reasonably applicable to the duststorm occur at Middle East, the fade margins have been estimated for duststorm on microwave links of 20 $\mathrm{km}$ at $\mathrm{C}, \mathrm{Ku}, \mathrm{Ka}$ and $\mathrm{V}$-bands. Table 4 shows the fade margins in $\mathrm{dB}$ for microwave links of $20 \mathrm{~km}$ for different reliability objectives at Riyadh. From Table 4, it can be noticed that for $20 \mathrm{~km}$ microwave link the fade margin is equal to $8 \mathrm{~dB}$ due to duststrom with $4 \%$ of water conten for $\mathrm{C}$-Band at Riyadh with reliability objectives of $99.9 \%$. The fade margin rises to $64 \mathrm{~dB}$ for the same hop with reliability objectives of $99.999 \%$. Hence, to design reliable microwave links at $\mathrm{Ku}$ and higher bands in desert, the duststorm attenuation plays very significant role.

\section{CONCLUSION}

Based on long term duststorm visibility data recorded in Riyadh-Saudi Arabia, dust caused attenuation and fade margins by duststorm for microwave links have been investigated and presented. A proposed duststorm prediction model has been used to estimate dust fade with relative moisture content. It is concluded that if a severe duststorm are marked by high moisture content, it will severely limit the hop length at $10 \mathrm{GHz}$ and higher frequencies. These findings will be very useful information for microwave link designers at areas affected by duststorms and the optimum radio planning and link budget analysis can be obtained accordingly.

\section{REFERENCES}

Alhaider, M., 1986. Design considerations for millimeter wave radio links in arid land. Int. J. Infrared Millimeter Waves, 7: 1559-1570.

China Daily, 2009. Sandstorm hits Riyadh of Saudi Arabia. Sina Corporation. http://english.sina.com/world/p/2009/0310/224892. $\mathrm{html}$

Crane, R.K., 1971. Propagation phenomena affecting satellite communication systems operating in the centimeter and millimeter wavelength bands. Proc. IEEE., 59: 173-188. 
Elshaikh, Z.E.O., M.R. Islam, O.O. Khalifa and H.E. Abd-El-Raouf, 2009. Mathematical model for the prediction of microwave signal attenuation due to duststorm. Prog. Electromagnet. Res. M., 6: 139153. DOI: 10.2528/PIERM09021906

Ghobrial, S.I., 1980. Effects of hygroscopic water on dielectric constant of dust at X-band. Elect. Lett., 16: 393-394.
Sharief, S., 1995. Chemical and mineral composition of dust and its effect on the dielectric constant. IEEE Trans. Geosci. Remote Sens., 33: 353-359. DOI: 10.1109/36.377935

Wesely, J., A. Hakola and G. Brooks, 2002. Assessment of the Dust Transport Application (DTA) over Africa, central and southwest Asia. Air Force Weather Agency, Offutt, AFB, NE 68113. 